\title{
A DOCUMENTAÇÃO DO SPI E A EDUCAÇÃO ESCOLAR NAS RESERVAS INDÍGENAS
}

\author{
Carlos Magno Naglis Vieira ${ }^{1}$, Lenir Gomes Ximenes ${ }^{2}$
}

\section{Situando o documento}

O trabalho com documentos históricos é sempre um desafio, pois requer inúmeros olhares "outros" do pesquisador. Olhares que precisam de atenção para desconstruir a visão eurocêntrica de mundo, a compreensão de novos conhecimentos inferiorizados e negados pela colonialidade, promovendo o diálogo entre eles (WALSH, 2009), e, ainda, procurar mostrar o protagonista da população em discussão e a sua própria história (VIEIRA, 2015).

Os documentos em discussão, todos do Serviço de Proteção ao Índio/SPI, encontra-se no Centro de documentação indígena "Antônio Brand" no Núcleo de Estudos e Pesquisa das Populações Indígenas/NEPPI na Universidade Católica Dom Bosco/UCDB. As reflexões correspondem as ações do Projeto de pesquisa "A relação entre a formação de professores, os projetos políticos pedagógicos e a organização curricular em escolas indígenas Guarani e Kaiowá de Mato Grosso do Sul”, aprovado no edital EDUCA/FUNDECT e no Programa Institucional de Bolsas de Iniciação Científica/PIBIC da Universidade Católica Dom Bosco/UCDB. É importante registrar que a pesquisa no qual resulta esses escritos, constitui um subgrupo de um projeto maior intitulado FORMAÇÃO DE PROFESSORES INDÍGENAS GUARANI E KAIOWÁ EM MATO GROSSO DO SUL: relações entre territorialidade, processos próprios de aprendizagem e educação escolar com financiamento do Observatório da Educação Escolar Indígena/CAPES/INEP/MEC.

\footnotetext{
${ }^{1}$ Históriador. Doutor em Educação. Professor do Programa de Pós-Graduação em Educação da UCDB.

${ }^{2}$ Doutora em História. Professora do curso de História da UCDB.
} 


\section{Reflexões a partir da documentação do SPI}

Como resultado dos movimentos sociais que eclodiram a partir da década de 1970 e das lutas dos povos indígenas, a Constituição Federal de 1988 em seu artigo 231 passou a garantir aos indígenas o direito à sua organização social, seus costumes, suas línguas, suas crenças e aos seus territórios de ocupação tradicional (BRASIL, 1988). O Estado brasileiro abandonou, ao menos oficialmente, o paradigma assimilacionista, que tinha como objetivo o apagamento das distintividades étnicas desses grupos. Com essa importante mudança, abriu-se o caminho para a construção da Educação Escolar Indígena diferenciada, específica, comunitária, bilingue e intercultural.

Todavia, é preciso considerar que as iniciativas de educação formal voltadas para os povos indígenas, ao longo da maior parte da história do Brasil, estavam pautadas pelos ideais positivistas, atrelados a uma política de integração nacional e de assimilação pela sociedade envolvente. A crença de que o intenso contato levaria as populações indígenas à extinção de suas culturas, possibilitou aos órgãos responsáveis pelas escolas desenvolverem mecanismos para a transmissão de valores que se contrapunham aos saberes tradicionais, como apontam Nascimento e Vieira (2011).

Nesse contexto, insere-se o Serviço de Proteção aos Índios - SPI, órgão indigenista que atuou entre 1910 e 1967. No início do século XX o SPI criou as Reservas, áreas indígenas administradas pelo órgão, com territórios muito menores do que os que os indígenas tradicionalmente ocupavam. Tassinari (2008) pontua que o passo seguinte era a implantação de escolas e o desenvolvimento de ações para 'civilização' dos indígenas visando sua preparação como 'trabalhadores nacionais'. A autora salienta que nesse período, a educação escolar tinha como foco o ensino da Língua Portuguesa e noções de Matemática para o comércio, também eram transmitidas técnicas de agropecuária.

A documentação do órgão indigenista compõe-se de relatórios gerais, elaborados pelos Chefes de Posto, nos quais constam informações sobre as escolas; ofícios; correspondências; memorandos; além de documentos escolares como relatórios elaborados pelas professoras, listas de chamadas, atividades e provas. Essa 


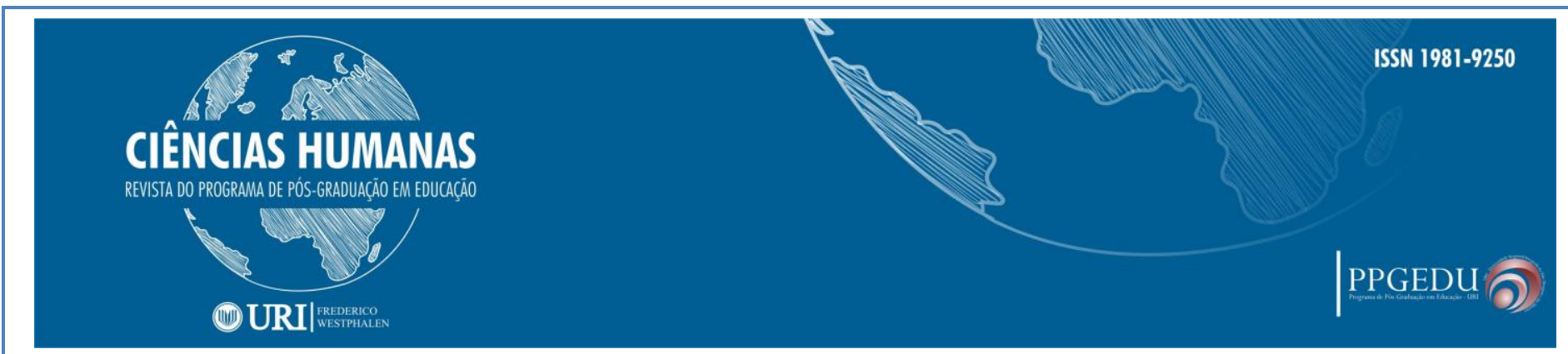

documentação demonstra a concepção educacional e indigenista do Estado brasileiro entre as décadas de 1910 e 1960.

Para este texto foram selecionados três documentos referentes à área dos Kaiowá e Guarani, do Posto Indígena José Bonifácio (atual Terra indígena de Caarapó, aldeia Tey'ikue), sul do antigo Mato Grosso, atual Mato Grosso do Sul.

O documento 1 data do ano de 1956, é um memorando do chefe da $5^{a}$ Inspetoria Regional do SPI, I. R. 5 (área de abrangência do sul do antigo Mato Grosso), ao chefe do Posto Indígena José Bonifácio:

\section{Documento 1}

Campo Grande, MT.

Em 11 de junho de 1956.

Ao Sr. Encarregado do P. I. José Bonifácio

Só hoje nos é dado acusar o recebimento do vosso memorando $\mathrm{n}^{\circ} 14$, de 11 de maio, aqui chegado no dia 22 desse mesmo mês. Veio o mesmo acompanhado de 4 provas dos alunos Salvador Vilhalba, João Modesto, Panta Sava e Argemiro Isnarde, todos bastantes fracos, notamos também que a frequência dessa escola tem diminuído consideravelmente. Bem compreendemos como são os indios refratários, e depende de muita paciência, dando-se conselho, fazendo se compreender as vantagens, incutir nos mais velhos, nos chefes, porque se o numero de alunos não fôr de 15 para cima, a escola periga ser suprimida, ou transferida para outro posto ou aldeia, e a desse como verá, nos meses de setembro e novembro, (faltou aviso de outubro) do ano passado, chegando a ter frequencia de 9 alunos, até é de admirar a Diretoria não chamar a atenção, e antes que isso aconteça, vamos nos prevenir, tudo fazendo para que não venha acontecer a suspensão da escola, tendo, como deve ter, muitas crianças em idade escolar.

Confiante que este aviso seja como de costume atendido de bôa vontade apresento-vos,

Saudações

Deocleciano de Souza Nenê

Chefe da I. R. 5

Fonte: Acervo SPI, Inspetoria Regional 5, Posto 092 - José Bonifácio, caixa 15, planilha 135, doc. 1-2. Disponível em: 


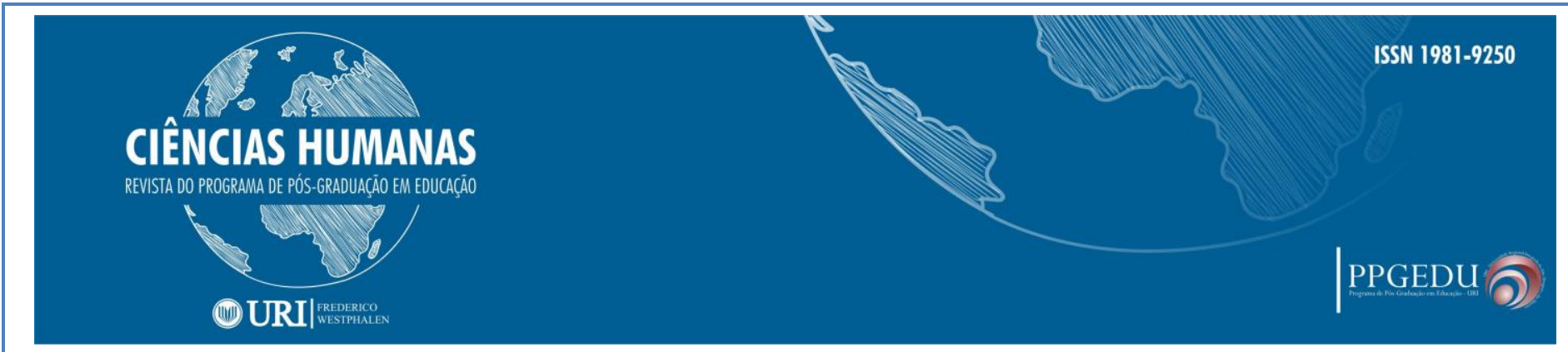

http://www.docvirt.com/docreader.net/DocReader.aspx?bib=MI _Arquivistico.

A leitura do documento nos faz perceber que o chefe da I. R. 5, que fazia parte do quadro pessoal administrativo do SPI, manifestou preocupação com o aprendizado dos estudantes do Posto, embora sem o conhecimento pedagógico necessário, qualificando-os como 'fracos'. O funcionário evidencia a visão do próprio órgão indigenista ao afirmar que 'os índios são refratários' para justificar o elevado número ausências nas aulas. Embora ele cobre providências de outro funcionário administrativo em relação à evasão escolar, não consta na documentação nenhuma reflexão acerca desse processo como resultado de uma educação impositiva e distante do cotidiano e da cultura dos Kaiowá e Guarani.

Realizando um olhar a partir dos estudos do campo pós-colonial podemos refletir esse momento como "um conjunto de relações de poder que hierarquizam os lugares e suas gentes, classificando-os de acordo com um suposto grau de evolução e desenvolvimento societário" (PORTO GONÇALVES e QUENTAL, 2012, p. 07). Mesmo não havendo uma formação pedagógica por parte do funcionário, observamos que a classificação dos estudantes indígenas acabam acontecendo.

A principal preocupação demonstrada no documento 1 é o risco de fechamento da escola devido à falta de alunos frequentes. A escola foi mantida e o número de estudantes matriculados aumentou, como aponta o documento 2. No entanto, a questão da ausência dos alunos continuou sendo pauta de outros textos. A seguir, a transcrição do documento 2, um fragmento de um relatório geral do chefe de posto, de 12 de dezembro novembro de 1963.

\section{Documento 2}

$[\ldots]$

Escola

A escola deste Posto, funcionou regularmente, com matricula de 45 alunos, mas com pouca frequência, as faltas eram justificadas alegando diversos motivos, principalmente falta de roupas. Os alunos assíduos tiveram bom aproveitamento, demonstrando 


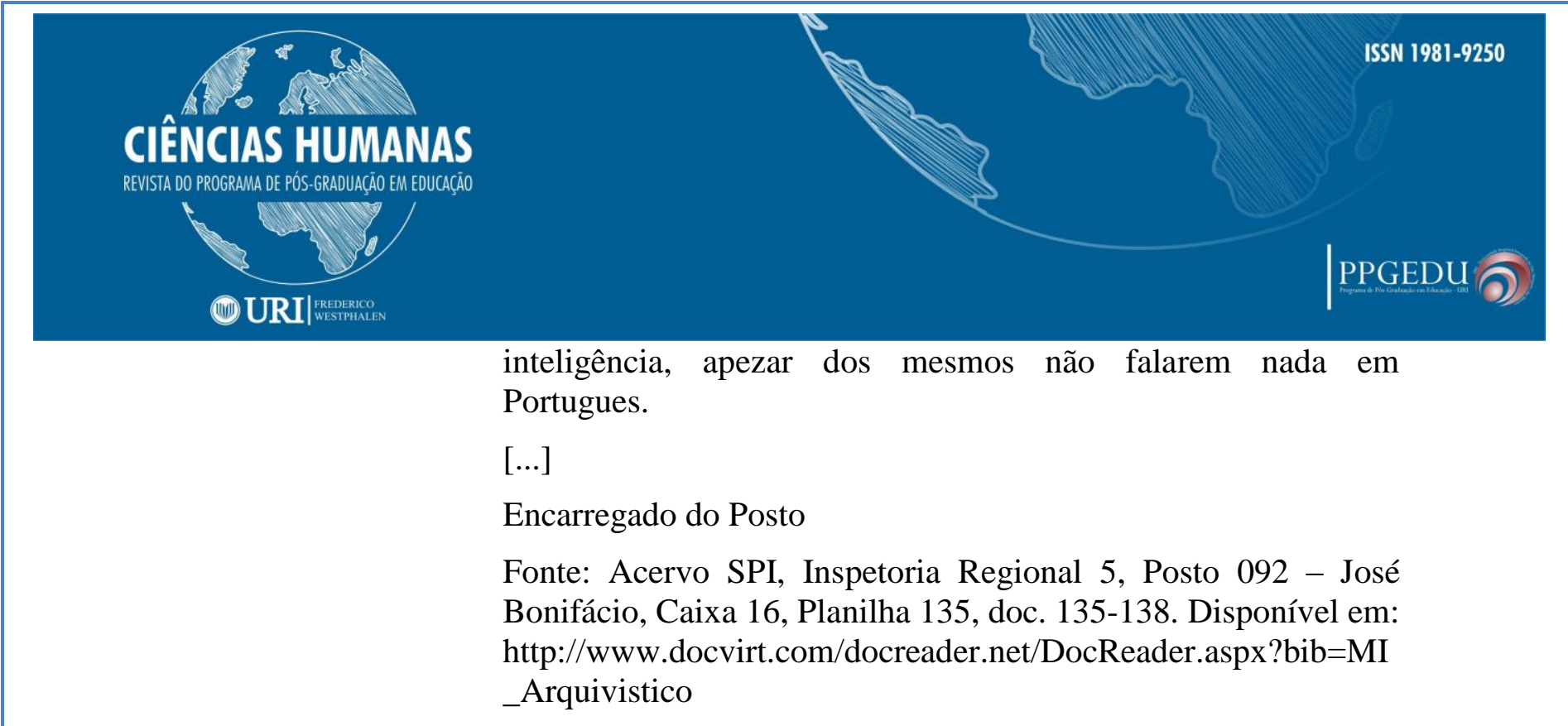

O documento 2 evidencia a preocupação do Chefe de Posto em mostrar que o aprendizado na escola ocorria conforme o esperado pelo SPI. Entretanto, a questão das faltas é novamente apontada e como justificativa aparece a 'falta de roupas'. Nesse caso, é pertinente o questionamento: o problema seria a escassez de recursos das famílias Kaiowá e Guarani ou ainda a imposição da escola em relação a um determinado tipo de vestimenta desconectado da cultura desses povos?

Não pretendemos nesse momento colocar em discussão a difícil história do povo Kaiowá e Guarani, mas gostaríamos de evidenciar como a articulação do poder se desata e se desenvolve por meio da elaboração de um discurso ou manifestação. Esses discursos se formam, se configuram, se produzem e se propõem novos olhares de classificação e de ordem social (QUIJANO, 2005, 2007; WALSH, 2009; PORTOGONÇALVES e QUENTAL, 2012).

$\mathrm{O}$ autor do documento 2 coloca em contradição a questão do aprendizado quando pontua que os estudantes não falavam a Língua Portuguesa. Por outro lado, toda a metodologia das escolas mantidas pelo SPI era monolíngue em português. Como poderia ocorrer o processo de ensino-aprendizagem de forma satisfatória se o corpo docente se expressava em português e os discentes em língua guarani?

A seguir, a transcrição do documento 3, um relatório elaborado pala professora da escola José Bonifácio, em 1966:

\section{Documento 3}

Relatório das atividades da escola José Bonifácio durante o mês de abril

Programa de ensino 


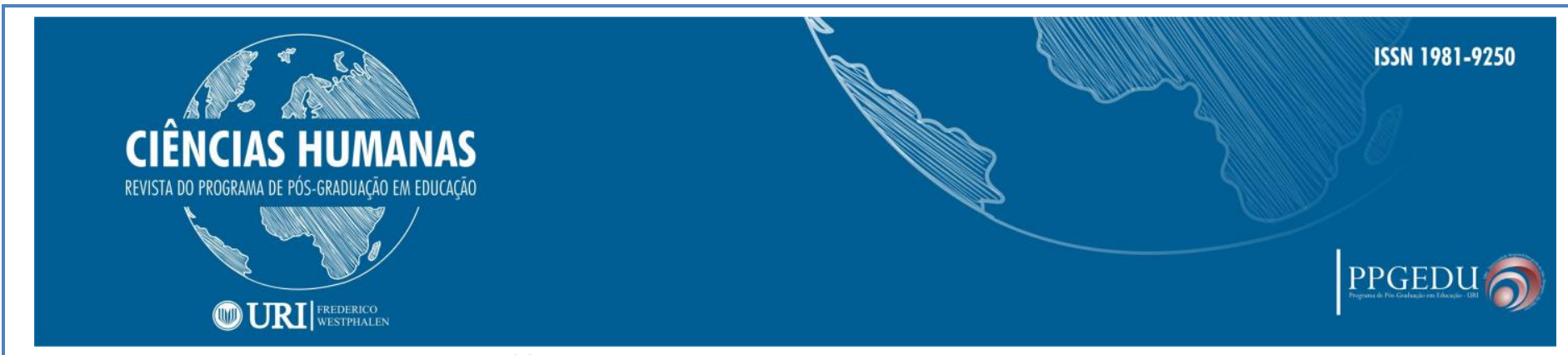

$2^{\circ}$ ano

História

Descobrimento do Brasil, ano, mês e dia. Os habitantes, primeiro e segundo nome dado ao Brasil.

Português

Ditado, cópia, separar cilabas, completar sentença.

Geografia

Conhecimento de cidades, estados e municípios.

Ciências

Animais vertebrados e invertebrados de que são úteis os animais, de onde nascem as plantas.

\section{Matemática}

Pequenos problemas, contas de somar, dividir, multiplicar e diminuir. Algarismos romanos de 1 a 100.

$1^{\circ}$ ano $\mathrm{C}$

Cópia número de 1 a 15 e contas de somar.

$1^{\circ}$ ano B

Abecedários e números de 1 a 50 .

$1^{\circ}$ ano A ou principiantes

As vogais e os números de 1 a 10 .

Deixaram de fazer sabatina 31 alunos, uns por estarem doentes, outros por serem principiantes e outros por não comparecerem às aulas.

Necessitamos de vasilhames para o preparo da merenda escolar.

Continua o trabalho no rancho da escola do Bocajá, que já se acha quase pronto.

Posto indígena José Bonifácio, 30 de abril de 1966.

Adir Lanzarini Silva

Professora

Fonte: Acervo SPI, Inspetoria Regional 5, Posto 092 - José Bonifácio, Caixa 15, planilha 137, doc. 168-169. Disponível em: http://www.docvirt.com/docreader.net/DocReader.aspx?bib=MI _Arquivistico 


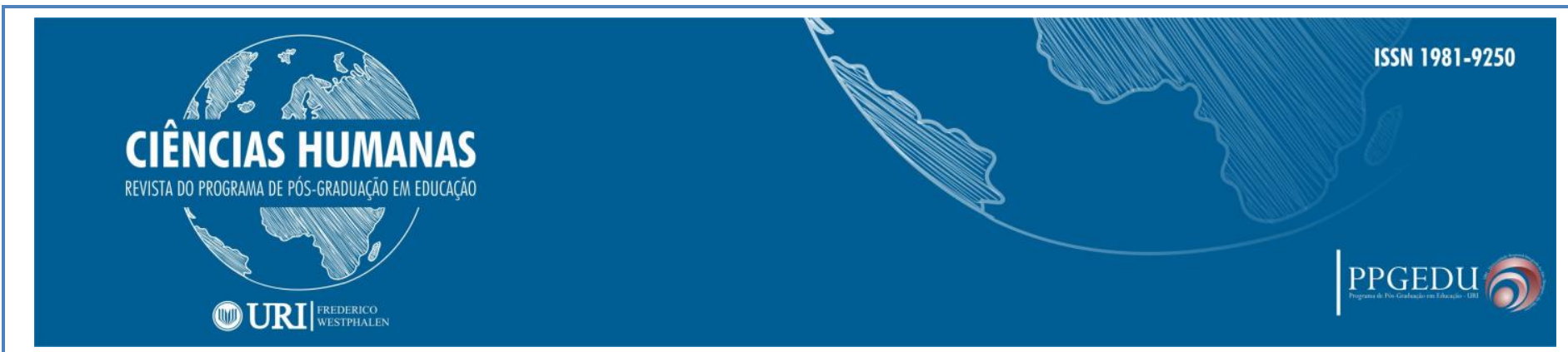

Observa-se que as temáticas de História, Geografia, Ciências e Matemática, são descontextualizadas do cotidiano e da cultura dos alunos Kaiowá e Guarani. Destaca-se a disciplina de História, focada no 'Descobrimento do Brasil'. Isto reduz a história do território kaiowá guarani à conjuntura de ocupação colonial portuguesa.

Por fim, ressalta-se que a ausência dos alunos continuava como problema persistente. É apontado um número de 31 alunos que deixaram de fazer uma atividade avaliativa, denominada sabatina (método de revisão de matéria, feito de forma oral). A ausência é justificada por vários motivos: doença, alunos ainda iniciantes ou desistência de frequentar as aulas. As constantes faltas dos estudantes indígenas na escola do posto Indígena José Bonifácio, colocam em pauta atualmente o fator linguístico e a tentativa de homogeneização cultual, como alguns dos responsáveis pelos problemas da educação escolar nas áreas indígenas ao longo do século XX.

\section{REFERÊNCIAS}

BRASIL. Constituição da República Federativa do Brasil. 1988.

NASCIMENTO, Adir Casaro Nascimento; VIEIRA, Carlos Magno Naglis. A escola indígena guarani e kaiowá em Mato Grosso do Sul: experiência emancipatória de educação indígena. In.: Anais do XXVI Simpósio Nacional de História. ANPUH, São Paulo, julho 2011.

NENÊ, Deocleciano de Souza. Memorando do Chefe da I. R. 5 ao encarregado do P. I. José Bonifácio, em 11 de junho de 1956. Acervo SPI, Inspetoria Regional 5, Posto 092 - José Bonifácio, caixa 15, planilha 135, doc. 1-2. Disponível em: http://www.docvirt.com/docreader.net/DocReader.aspx?bib=MI_Arquivistico. Acesso em: 7 set. 2018.

PORTO-GONÇALVES, Carlos Walter; QUENTAL, Pedro de Araújo. Colonialidade do poder e os desafios da integração regional na América Latina. Revista Polis, n. 31, p. 128, 2012. URL: http://polis.revues.org/3749

QUIJANO, Aníbal. Colonialidade do poder, eurocentrismo e América Latina. In: LANDER, Edgardo (org.). A colonialidade do saber: eurocentrismo e ciências sociais:perspectivas latino-americanas. Buenos Aires: CLACSO, set. 2005. p. 107-130. (Colección Sur Sur).

QUIJANO, Aníbal. Colonialidad del poder e clasificación social. In: CASTRO GÓMEZ Santiago; GROSFOGUEL, Ramón (Orgs.). El giro decolonial: reflexiones para una 


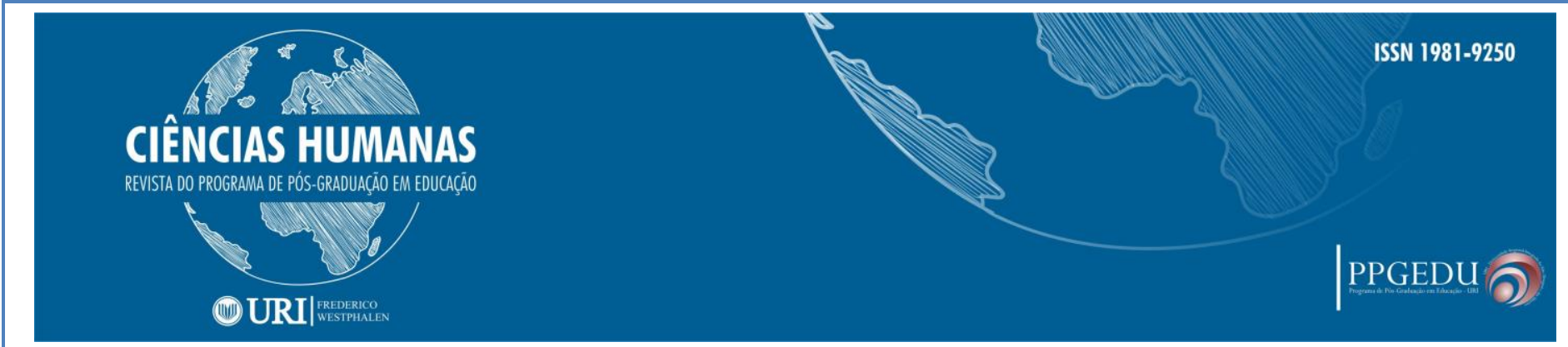

diversidad epistémica más allá del capitalismo global. Bogotá: Universidad JaverianaInstituto

SILVA, Adir Lanzarini. Relatório das atividades da escola José Bonifácio durante o mês de abril, 30 de abril de 1966. Fonte: Acervo SPI, Inspetoria Regional 5, Posto 092 - José Bonifácio, Caixa 15, planilha 137, doc. 168-169. Disponível em:

http://www.docvirt.com/docreader.net/DocReader.aspx?bib=MI_Arquivistico_Acesso em: 7 set. 2018.

SILVA, D. Relatório do encarregado do P. I. José Bonifácio, em 12 de dezembro de 1963. Acervo SPI, Inspetoria Regional 5, Posto 092 - José Bonifácio, Caixa 16, Planilha 135, doc. 135-138. Disponível em:

http://www.docvirt.com/docreader.net/DocReader.aspx?bib=MI_Arquivistico. Acesso em: 7 set. 2018.

TASSINARI, Antonella Mana Imperatriz. A educação escolar indígena no contexto da antropologia brasileira. In.: Ilha Revista de Antropologia, v. 10, n. 1, 2008.

VIEIRA, Carlos Magno Naglis. A criança indígena no espaço escolar de Campo Grande/MS: identidade e diferença. Tese (Doutorado em Educação) - Universidade Católica Dom Bosco/UCDB, Campo Grande/MS, 2015.

WALSH, Catherine. Interculturalidade, crítica e pedagogia decolonial: in-surgir, reexistir e re-viver. In: CANDAU, Vera Maria (Org.). Educação intercultural na América Latina: entre concepções, tensões e propostas. Rio de Janeiro: 7 Letras, 2009. 